\title{
The Strategic Importance of Enterprise Resource Planning (ERP) Systems Implementation in The Fast Moving Consumer Goods (FMCG) Industry in Sri Lanka
}

\author{
H M R P Herath, S I Wijenayake
}

\begin{abstract}
Enterprise Resources Planning Systems (ERP) are implemented in organizations to optimize the supply chain to improve the overall performance. Yet, it is observed that many organizations have not achieved the desired level of performance through this strategic move. Literature suggest that the implementation barriers can be a main reason for this. Hence the problem centered in this study is to identify the success factors and challenges of ERP systems implementation in the FMCG industry in Sri Lanka. This study uses the case study approach for four companies in the FMCG industry. Focus group interviews were used to gather data and the participants of the focus group interviews were key users who had an important role during the implementation. Semi-structured interviews were conducted by an experienced interviewer using an interview guide with semi-structured questions. Success factors included the technological know-how, high management commitment, lesser government regulations, and experience of the process re-engineering. Challenges included investment in resources, information management, changing the organization culture to the best practices of the system, lack of the user training and limitation of the proper consultancy services. Findings of the study can be used as a framework to understand the ERP implementation success factors and the potential challenges faced by organizations in the FMCG industry.
\end{abstract}

Index Terms: Enterprise Resource Planning; Fast Moving Consumer Goods Industry; Implementation Strategies; Success Factors of ERP Implementation; Challenges of ERP Implementation

\section{INTRODUCTION}

Modern business environment is sophisticated with the use of new technology. Businesses use various systems integrated with computer technology to handle their business processes. Main business processes in organizations are inventory management, production planning, quality management, human resource management, financial management and customer relationship management. Organizations use information systems to control these processes. Modern business is using Enterprise Resource Planning (ERP) systems to cover all the

Revised Manuscript Received on September 22, 2019

H M R P Herath, Department of Marketing Management, University of Kelaniya, Sri Lanka (H M R P Herath), renukaherath@kln.ac.lk

S I Wijenayake, Department of Marketing Management, University of Kelaniya, Sri Lanka (S I Wijenayake) functions. ERPs integrate various functional spheres in an organizations with a link to the entire supply chain. Further, its aimed at implementing best industry practices for providing the right product at the right place at the right time cost effectively (Nemati \& Mangaladurai, 2014). Effective ERP systems help to enhance the supply chain management by integrating internal business processes, enhancement of information flow among different departments , improvement of company's relationships and collaboration with suppliers, customers, and supply chain partners, global sourcing, sharing, exchange and movement of information, goods and services, improvement of product quality, flexibility and customer responsiveness, and finally reduction of inventory and operation costs (Shatat et al., 2012). According "2016 report on ERP systems and enterprise software" conducted by Panorama Consulting Solutions in 2016, there are some reasons to implement the ERP systems in an organization. Those are replacing legacy system, position company for growth, improving business performance, reporting or regulatory compliances, make employees' job easier, standardize global operations, reduce working capital, better serve customer. Systems, Applications and Products (SAP), Oracle, Infor, Sage, Microsoft, Epicor, TOTVS are the prominent ERPs used in business world in common.

\section{A. Erp Systems}

Information systems are interconnected modules functioning together to gather, process, store, and distribute information to support resolution making, coordination, control, analysis, and pictures in a business (Bourgeios, 2014). An information system has five modules such as hardware, software, data, people, and process. These information systems consist of two categories, personal information systems which can manage and store information for a private person and second information system is an enterprise information system that tailored toward the support of an organization. An ERP is an information system that cares the main business procedures of an organization human resource management, sales, marketing, management, financial accounting, controlling, and logistics. ERP systems are big and complex software systems that incorporate 
smaller and more focused applications; for example, most ERP systems include functionality such as procurement systems, manufacturing systems, sales and marketing systems, delivery systems, finance systems, workflow management systems, data ware houses and business intelligence systems.

\section{B. FMCG Industry}

Fast Moving Consumer Goods (FMCG) are defined as goods which are sold quickly at comparatively low costs. There are some features to identify FMCG industry. Different products with small value which customers tend to purchase very frequently, and consumer does not spend too much time to make choice about buying the goods, FMCG products come in wide variety and often cater to necessities, comfort and luxury items (Singh, 2014). In FMCG markets, one of the important resources is the number of customers because of sales volume effect on the ability for bargaining the part of another key resource (display shelf) with sellers. Their revenues also put up with the expenditure on advertising, which is essential for building customer loyalty. FMCG establishments face difficulty of forecasting the upcoming demand. Predicting process of the demand predominantly consisted of the communication, organization, information and estimate generation. Communication established on the internal, external and technological advances. Internal communication basically used for the estimate throughout the business, external communication estimate based on the communication amongst the consumers and suppliers of an organization. Technological improvements made the linkage between the internal and external communication. Demand forecasting of an FMCG organization have to grab more information around history of demand (Adebanjo et al., 2000). In the FMCG industry, enterprises face a very difficult, if not most difficult, task developing a competitive benefit based on differentiation or low-cost strategies. The leading reason is that competitors match or, even overtake innovations and costs drops in a very short period (Kunc, 2005).

\section{Erp Implementation Strategies}

Implementation of ERP is a complex exercise, and many adopters have come across problems in different stages. Many cases of the failure to implement ERP because of either terminations or cost and time overruns have been reported. An ERP execution can take many years to complete and expenses tens of millions of dollars for a modest size firm and greater than the hundreds of millions of dollars for large organizations. Even though the benefits of a properly implemented ERP system are important, the price of a poorly implemented system is also great. Approximately $90 \%$ of ERP system implementations were late or above budget and the achievement rate of ERP systems implementation was merely about 33\% (Mishra \& Mishra, 2010). Even though ERP systems have a significant impact on organizational performance, the relative impact is varied according to the type of industry or business. Some of the organizations in the FMCG industry have implemented ERP systems in order to meet customer requirements and key performance indicators. In Sri Lankan context large scale manufacturers like Unilever Sri Lanka, Hayleys, Ceylon Biscuits Ltd. Nestle Lanka, Cargills PLC, Ceylon Cold Stores, Maliban Biscuit Manufactories Ltd. etc. have invested a large amount of money to implement ERP systems. However, no sufficient empirical evidence is found to define the degree of impact of ERP systems on the organizational performance (Rajapaksha \& Seddon, 2005). Literature implies, there are some barriers to implementing ERP system in organizations in Sri Lanka (Madurapperuma et al., 2009). Hence the problem centered in this study is to find out the strategic importance of implementing ERP in an organization through identifying the success factors and difficulties of ERP systems implementation in the FMCG industry in Sri Lanka.

\section{1.4 Research Questions}

1. How is the prevailing situation of the ERP system implementation in FMCG industry in Sri Lanka?

2. What are the successful factors in favour of implementation of the ERP in the FMCG industry in Sri Lanka?

3. How some specific factors resist to the implementation of an ERP system in Sri Lankan FMCG organizations?

4. Why it is important the implementation of ERP system in FMCG industries in Sri Lanka?

\section{LITERATURE REVIEW}

\subsection{There are Some Features To ERP Implementation}

There are Some Features To ERP Implementation project to be a success, some of those are, top management has to show their commitment to the entire organization, and particularly to the project team, involvement of the co-workers participation in the implementation process, ERP implementation requires the complex coordination of people, process, and technology, internal and external team members need to be professionals of their subject matters (Agarwal, 2014). The technological implementation part acts as a significant role in designing operational and route technologies but also in management of the whole production process, the smooth performance of the resource management system as a fragment of more wide e-manufacturing system for the products flow through the production process with the aim to optimize production costs and that can help to minimize the lead time and building up structural design for e-manufacturing system software (Loun, 2011).

Successful use of enterprise systems to enhance business value across the business network linked its suppliers, stockiest and retailers through an extended enterprise system to form a business network system, which has resulted in remarkable cost savings for the company (Jaiswal et al., 2005). Successful ERP implementation must be a plan with the consultant team, team 
plan, pronouncement to the all the employees in an organization, taking part of the employees, business process mapping, implementation plan, tracing implementation and evaluation of the implementation (Almgren et al., 2014). ERP system implementation has critical achievement factors to identify the corrective implementation process in the organization. Those factors can be categorized into three phases: pre-implementation or setting-up phase, implementation, and post-implementation or evaluation phase (Motwani et al., 2005) (Figure 1).

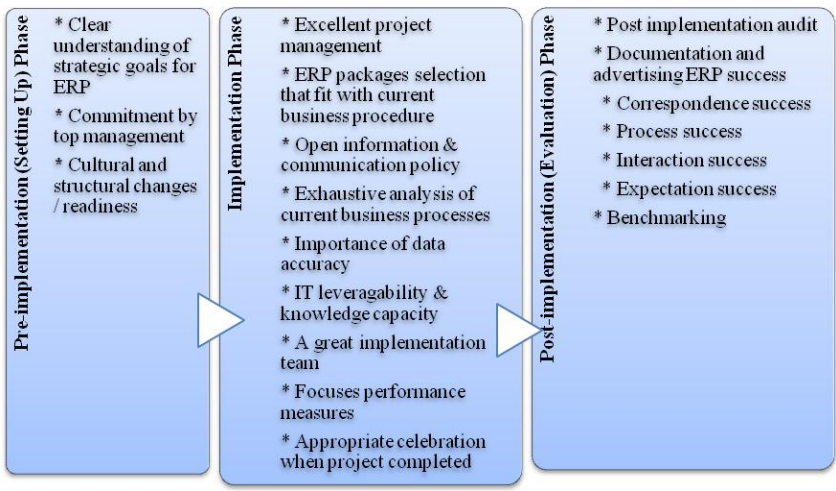

Information systems usually have two development processes. As the first development process, a generic information system is executed; in the second development process, system is customized. Implementation of the ERP system is directed by the development process of the software vendor. Soon after an organization obtaining an ERP system that ERP system passes over the development process of the organization. In the second development process, the ERP system wants to be installed, configured, modified and introduced in the organization. ERP system has development life cycle, it is described in the texts and used in practice (Figure 2).

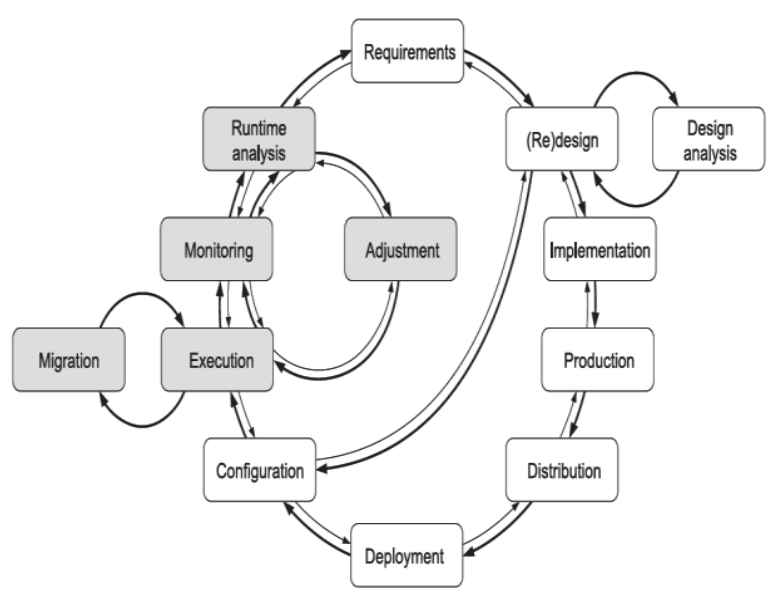

Figure 2: The life cycle model of an enterprise information system (Source: Lee \& Seshia, 2016)

\section{A. Critical Factors of Successful ERP System Implementation}

According to Dunaway (2015), there are some sort of sustain strategies of the ERP implementation project. There are project drivers, project management, project resources, ERP functional modules, existing platforms, systems and data and cost allocation.

\section{B. Critical Factors of Successful ERP System Implementation}

Implementing an ERP system is not a cheap or risk-free venture. It is therefore meaningful to examine the factors that, to a great extent, decide whether the implementation will be fruitful or not. According to Umbel et al., (2003) a variety of features that can be considered being critical to the achievement of an ERP implementation. Factors identified are: Clear understanding of strategic goals, commitment by top management, excellent project management, organizational change management, a great implementation team, data accuracy, extensive education and training, focused performance measures performance and multi-site issues It is possible to adjust the ERP system to fit the advanced commercial processes, this is a contested area in both industry and academic world. Most ERP systems are prepared to be configurable and this is the required method for most organizations. ERP systems increase economic growth, as measured by return on assets (ROA), return on investment (ROI), and asset turnover (ATO). There is some value adding actions arising from the implementation of the fresh ERP system of the FMCG organizations. Those are; improve competitive advantage of the company (Fosser et al., 2008), and inventory optimization by reducing lead time (Palawtta \& Perrera, 2016), inventory optimization by reducing total inbound logistics costs (Palawtta \& Perrera, 2016). Organization needs to monitor and track key performance indicators (KPIs) that are critical in measuring business success. Business Metrics tracks the keys to the performance management second-by-second. It is a method assisting a business to achieve their objectives by planning critical performance goals and evaluating progress towards those goals. It is frequently applied at every level of the business. Performance management comprises strategic plans, and the objectives required to achieve those plans. At a comprehensive level, it contains targets for manufacturing procedures with key indicators related to uptime, defects per run, cycle times and other. Performance management drive results from end to end concentrated execution of strategies through all levels of business, giving an improved visibility and control. Industrialists have immensely upgraded their operations in recent years with the integrated use of ERP, innovative data collection, and other manufacturing developments. Nowadays, the best manufacturers have recognized a need to combine the widespread quantity of data they receive into entirely novel insights.

\section{ERP System Implementation in Sri Lankan FMCG Industry}

The implementation of ERP is affected by two broad kinds of factors such as national or environmental and organizational or internal factors. The internal issues are the maturity of the information technology, availability of computerized culture in an organization, 
the size of the business and the management commitment. The outside factors influence to the implementation procedure are the economy and economy growth of the country, infrastructure improvement of the country, manufacturing strength, government rules and cultural influence from the society (Carolina, 1992). FMCG industry has danger in the supply chain process, because of that risk is well-defined by the negative impact increased by the probability of an incident, focus only on the negative aspects and disregard the opportunities. The supply chain processes consist of flows of finances, materials, and information. This can be considered as an end-to-end view of those flows within the company with interfaces to dealers and customers (Diehl, 2013). According to earlier studies FMCG industry want systematic ways to process supply chain actions. Sri Lankan businesses were having waste material movement, idle time and bottleneck sectors in the manufacturing process (Gayan et al., 2015). Therefore, there is a requirement of addressing those issues. Literature suggests ERP as a potential solution for those issues.

In the Sri Lankan context that the implementation of ERP systems was less than $7 \%$ compared with the global implementation. There are some factors that have contributed to this concern, differences in relative wealth of organizations compared with global, relatively low per capita income of the country and the ERP systems are more expensive, limited infrastructure development, high expectations of the individuals and organizations, an ERP system imposed its own logic on a company's strategy, culture, and organization. ERP implementations in Sri Lanka were mostly done for large and medium scale organizations on the island. In the global market, these organizations are categorized as small and medium scale. These implementations were done with limited resources, lack of computer literacy and language problems and cultural issues and without properly evaluating their capabilities and competence (Madurapperuma et al., 2009). There are some selection process and implementation process for implement suitable ERP system in an organization. In the selection process and the implementation process organization need to evaluate vendor and software reputation, cost and financial availability, align with business functions, chief executives countenance, experience in same business domain, availability of domain expert, support \& training and vendor-employee interaction, level of customization, organization culture and implementation plan and duration, implementation team and end-users specially project managers and project staff interest, usability and user friendliness, based technologies, size of the organization/ projects and level of business process re-engineering, additional functions (backup, integration, reporting \& analysis features, real-time changes) and user agreement and licenses (Nanayakkara et al., 2015).

\section{METHODOLOGY/MATERIALS}

\section{A. Basis of the Research}

This study is employs the qualitative research method. Because of the findings of this study was based on the research questions, which are 'How is the current situation of the ERP system implementation', 'How are the strategies used in the implementation of the ERP system', 'How the factors resist to the implementation of an ERP system' and 'How the key performance indicators could be used to measure the performance in ERP systems'. According to research questions of this study was guided to the design emphasizes on the relationship and causality of variables of study. Then it is focused to how and why of phenomenon, and use it as a qualitative study (Abosede, 2016). A qualitative methodology as a systematic subjective approach used to define life experiences and circumstances to give them meaning (Burns \& Grove, 2003). Through this procedure, it is able to find out the familiarity of the participant's and significance of the ERP systems. The qualitative research emphases on the experiences of persons as well as highlighting the uniqueness of the individual (Parahoo, 1997).

The FMCG organizations selected by which were already implemented ERP system for their main system to control all the function of the organization. Since this research is designed to carry out by the selected cases with the real data in Sri Lankan context. Case study research technique is particularly well-matched to Information System research, since the objective of our discipline is the study of information systems in establishments, and "attention has shifted to organizational rather than technical issues" (Myers, quoted by Benbasat et al., 1987). A case study research practices interviews and documentary resources first and foremost, without using participant observation (Myers, 1997). Not only that but also the selection criteria were based on the coverage of different products categories which were manufactured by the FMCG in Sri Lanka. Those products were included to cover the product ranges of the personal care products, home care products, households and food \& beverages. According to that, the selection was limited to four organizations. According to Marshall (1996) there were some reasons, firstly, samples for qualitative investigations tend to be small. Secondly for an accurate random sample to be selected. Thirdly, random sampling of a population was possible to produce a representative sample only if the research characteristics typically distributed within the population. Fourthly, it was well acknowledged by sociologists that people were not similarly good at observing, understanding and interpreting their own and other people's conduct.

This study established on the judgment sample strategy and names of respondents were primarily determined by the management of every organization through establishment record based on their career responsibilities, position and participation in the subject studied. Though, respondents 
were also carefully chosen on the basis of the researcher's individual decision on the ground that they could deliver the necessary information needed for the research.

\section{B. 3.2 Method of Interviews}

This study based on the moderately semi-structured interviews to have flexibility to approach different respondents differently while still covering the same areas of data collection. The interviews were tape-recorded to ensure no information is missed out (Noor, 2008). Documentary evidences were used to cross-validate information collected in interviews (Myers, 1997). Additionally, documents provide guidelines in assisting the researcher with his inquiry during the interview. This study based on the multiple cases of FMCG organizations in Sri Lanka, because of that two or more cases should be included in the same study precisely because the investigator predicts that similar results will be found (Noor, 2008).

\section{Data Collection \& Analysis}

Primary data collection was done through interviews. Following steps were considering to selection of the participants. At the planning stage of the study, FMCG organizations which engaged in the business with implemented ERP were chosen from a names list given by one of prominent ERP provider with long time experience as an ERP provider in Sri Lanka. As the next step of the selection process the researcher tried to find out four organizations to cover the manufacturers of different consumer product categories like Home care, Personal care, Pharmaceuticals and Food items. Researcher approached the above selected FMCG organizations and obtained the names of the project team members who were actively engaged in the implementation of the ERP in their organizations. Participants chosen from those lists who were executives familiar with the ERP implementation and the progress of the project in the organization. Researcher personally contacted the above selected participants and obtained their willingness to take part in his study voluntarily.

Selection of the focus group of the research by the contact of a FMCG organization and find out the project team member of the ERP system implementation team as well as the active participant of an ERP system in an organization. Participants of the focus group interviews were key users who had an important role during the implementation of the ERP system. Hence, a structured interview was planned and conducted. The interview guide comprised of semi-structured questions where a grand as well as mini tour questions were used. Grand tour questions were wide questions asked to introduce the topic such as "Which type of reasons effect for the shifting from the legacy system to implementation of an ERP system?" The mini tour questions were precise questions such as "What is the name of the ERP software you use in your organization?". Interview transcription scripts were sent to the participants for their cross validation.

\section{Methods of the Data Analysis}

A description of real practical information and nuances of all qualitative data analysis strategy is well away from the scope of a short paper, a common appreciation of the theoretical assumptions underlying some of the more common approaches can be valuable in understanding what a researcher is trying to say about how data were arranged, organized, conceptualized, refined, and understood (Thorne., 2000). This study was based on the thematic analysis method, qualitative approaches are incredibly diverse, complex and nuanced (Braun \& Clarke, 2006, quoted by Boyatzis, 1998), and thematic analysis should be seen as a foundational method for qualitative analysis (Braun \& Clarke, 2006).

This study flowed the five steps of thematic analysis proposed by Fereday \& Cochrane (2006) and those steps are, Step 01: Developing the Code Manual, Step 02: Summarizing Data and Identifying Initial Themes, Step 03: Applying Template of Codes and Additional Coding, Step 04: Connecting the Codes and Identifying Themes, and Step 05: Corroborating and legitimating coded themes

\section{E. Research Methodology}

This study uses an extended version of the framework suggested by Motwani et al., 2005. As described in the literature review, three ERP implementation phases are identified and the factors in each phase are described in detail below.
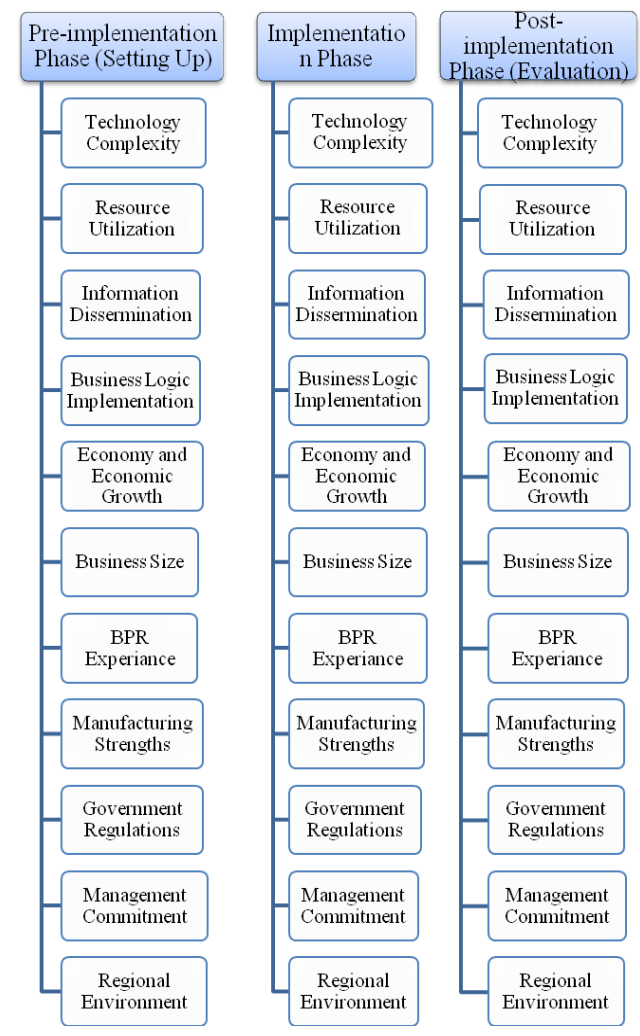

Figure 3: Combination with ERP Implementation Framework and Framework Evaluation Criteria

Represented in Figure 3 was used to recognize the effectiveness of the ERP resolution from the users' perspective in each and every phase of the ERP implementation.

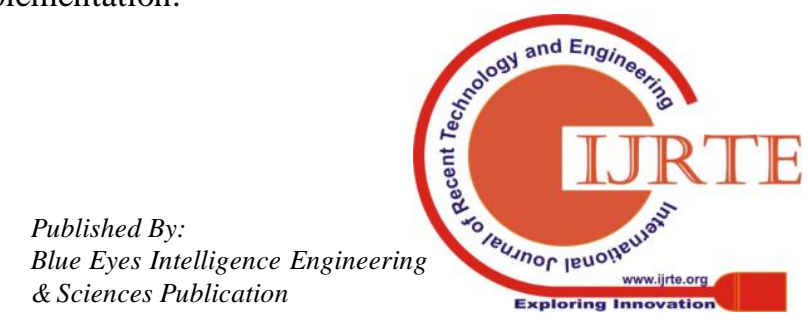


According to the above framework, the implementation of the ERP could be divided into three stages. To evaluate the strategic implementation of the ERP systems in FMCG industry in Sri Lanka, all the stages are important. This study has gone beyond of the findings by Rajapaksha \& Seddon (2005) the factors which influenced the low rate of adoption of ERP systems and these findings will be influenced on the FMCG industry in Sri Lanka.

1. The initial cost of ERP implementation is not within the reach of most organizations in Sri Lanka

2. National culture of Sri Lanka manifest at the organizational level is not geared to accept the culture imposed by the ERP software

3. The growth of ERP adoption in developing countries is severely affected by the shortage of information, awareness and ERP-trained human resources, unsuccessful projects, and uncertainty concerning agents appointed by the vendors

4. Staff reduction facilitated by ERP adoption clashes with cultural norms in the Sri Lankan labour market

An additional finding of Rajapaksha \& Seddon (2005) research study was learned from prevailing ERP adoptions in developing countries like as in Sri Lanka. Those are; ongoing cost of ERP adoption is not within the reach of most organizations, number of staff to be trained is higher in Sri Lanka compared to West even for the same organization size, level of integration provided by ERP is too high compared to expectations of individuals and organizations, requirement of customization to ERP software, lack of structured and disciplined business environments in developing countries like as Sri Lanka creates severe operational level problems in ERP implementations, and vendor support and knowledge of ERP products are low in Sri Lanka: there is few number of staff of local agents with inadequate knowledge on their ERP products. Therefore, it is hard to find trained personnel to support ERP products.

\section{F. Four Cases}

The Company ' $A$ ' was founded in 1878 and it was incorporated as a limited liability company in 1929 , becoming quoted on the local Stock Exchange in 1968. Company spans across a wide spectrum of activities, ranging from import, export, distribution and freight forwarding to hotel sector, plantation management and formulating and trading in chemicals. Their key activities include manufacture of "home care products such as mosquito coils, joss sticks, toiletries items and some mosquito repellents". This was recognized in Sri Lanka as a long standing organization that is dependable and stable, the Company was a dynamic organization that adapts to the latest technology and trends. Their strong relationships with other international partners have contributed to the development of export and import channels that exchange high-quality commodities. Company products were distributed around the country in partnership with island-wide dealer networks.

After a little more than a century from the establishment, they got fully integrated with an ERP system "on 1st of August 2016." According to a participant who was a manager of the company ' $A$ ' responded that the delay was not an actual delay but, "I feel it is the correct time to go for the ERP till that we know we are having evaluating, negotiating and you know analyzing the requirement. It's not delaying, but it is a process that we have been carrying out during last two to three years for choosing the most appropriate ERP business." The company ' $A$ ' is already having an ERP system, but it was not yet a fully integrated system to fulfill the requirement of an organization. He said that "the Main thing is Legacy systems that we didn't have this integrity also the power of the modules works independently and it was the batch type of process. That is one reason and another reason is visibility and availability of information at the user level. Previous Legacy systems most of the time the dependency was on IT, so we thought of bringing back to the business that, where the business can drive their businesses efficiently and effectively."

The company 'A' was used the SAP as an ERP system of an organization, as explained by the participant "How we select first look at the available ERP at that time. One was Oracle, one was SAP, other one was IFS and also the GPS system 21 newer version of ARORA. Evaluation criteria were one thing was the trend that the most of the organization were adapted. So, another thing was there, which was the most suitable ERP that gives the company requirement. Especially, the Asus FMCG company the sales area as well as purchasing and manufacturing. So, at that time the strongest software was found for the manufacturing was SAP. So, that one of the reasons we selected SAP. And also the newer Technologies that the application has used it was that in memory processing that is all, which is very fast access, analytical capabilities that the database itself had."

As the next step, they have to select implementation party to establish the newer ERP system in the organization. However, that the company ' $A$ ' selected a foreign party as the consultant of an ERP system. They explained the situation as that "Actually we looked at both parties, one was a local party and also there were couple of two foreign parties we evaluated. At that time the software that we implemented was a newer version of the SAP that is S/4 HANA, so the local party at that time didn't have much experience on S/4 HANA. That was one reason that we selected the foreign party who had the S/4 HANA experience, also the implementation wise they have done a lot of implementation than local party. Finally, cost factors also considered specially the skill levels of the consultants who come and deliver the product. Especially look at their experiences and their capabilities related to SAP implementation as well as their experience."

Considering above factors the company ' $A$ ' used integrated ERP system for improving their performance of the manufacturing system efficiently and effectively in their organization. The company ' $A$ ' was at the stage of post-implementation because they have already implemented the ERP system and used to that less than one-year period only. 


\section{Company B}

Company ' $\mathrm{B}$ ' had its beginning in 1848 when the partnership was founded by two pioneering individuals. Then the business activities were diversified and covered estate agencies, commission agents, imports \& exports, ship chartering, etc. In 1920, then the partnership was converted to a limited liability company and continued its business of being a primary exporter of tea and local produce. With the decline in the export business, the company shifted its focus to imports, Manufacturing, local sales and distribution of consumer products.

Company manufactures personal care products for the FMCG market. They manufacture a wide range of shavers including single, double, and triple blade razors, with a variety of grips and colours, for both men and women with highest quality and safety standards. Company created a massive impact in the FMCG market dominated by international brands as an example, toothbrushes created history in 1994 by pioneering Dupont Tynex 'antibacterial' bristles in the Sri Lankan market.

According to the Assistant Manager of the company 'B',such as toothbrushes, razors, shaving foam, shaving gel and hand wash." The company 'B' could be recognized as an old company in an FMCG industry in Sri Lankan market, but they established ERP system on "April 2016,". A participant pointed out that the reasons for the delaying the application of ERP, “.... we had a financial package and all other modules, but those were not directly inter-connected. So, in the month end we were passing all the entries to our financial package through the interface. At the same time in month end IT department facilitate all the required information from the system that is the one reason getting delayed to implement ERP. And also our staff also really satisfied with the existing system so there's no any requirement to move to the new system that's the thing lead to delay the implementation." The reasons for changing of the existing system to the new ERP was "... the previous system mainly based on the batch processing for the manufacturing. Financial module \& sales module always in real, so the information fetches any time but information not to the standard as like an ERP because it was not interconnecting to the all modules. Legacy system was individual modules we developed, and it was interconnected in to the month ends that was a one reason. And other reason was existing hardware infrastructure fully utilized, so we need to enhance hardware to run the business further, at that time management has two options, one was go with a new ERP, other one was go with existing system by increasing the hardware capacity. So, in the second option if we go for it the existing software with the new hardware that was not compatible with our existing software. Older version because it was 15 years' older version so that older version doesn't support the new hardware. So, our focus was the first option that go with a new ERP."

The company ' $\mathrm{B}$ ' has selected software SAP as an ERP system to fulfill all the requirement of the organization. The reasons for the selection of this product was "...during the ERP selection stage we checked the other ERP software available in Sri Lanka like, SAP, Oracle, Microsoft dynamics and IFS. As we were in the FMCG we have to think about the modules in the ERP that means SD, MM, FICO, PP, QM and PM but, some ERP's doesn't have all the modules. So, we identified two to three ERP systems, which have all modules. Other thing was we evaluate the competitor organizations. That means like same FMCG companies what they were using as the ERP. According to those observations we have chosen the SAP as a best suitable product for us." And also need to select implementation party to establish the newer ERP system in the organization. To complete that task, the company ' $\mathrm{B}$ ' has selected foreign party as the implementation consultant of an ERP system and local parties to as a business partner and hardware partner. She said that the reasons for selection of the supporting parties were, "For the implementation we got a local support to identify the process. They have prepared some documents and handover us what are the areas we have to implement, what are there we have to think and everything...."

To fulfil the requirements, considering above factors the company ' $\mathrm{B}$ ' decided to use integrated ERP system, which was SAP to improve their performance of the manufacturing system efficiently and effectively within the organization. The company 'B' was at the stage of post-implementation, because they have implemented ERP system only less than one-year period earlier.

\section{Company $\mathrm{C}$}

Company ' $\mathrm{C}$ ' was founded in 1956 as a subsidiary of one of Sri Lanka's pioneering pharma companies and count over 40 years' experience as an agency-distributor business operation lines. Strengths of the company ' $C$ ' are, mature experience and work-related expertise in agency representation, confidence and respect among the medical profession as a distributor of high-quality pharmaceutical products, high visibility in key high-yielding therapeutic product markets (CNS, skin, gastro, immunology, neuro, oncology and antibiotics), dedicated medical promotional teams, expert handpicked distributors and the well-structured sales and distribution team, rationalized distribution principle. The company operational structure allows the facilitation of new ventures and moves as per the set solid platform of Marketing, Sales and Distribution, Finance, Regulatory\& Supply Chain and IT.

Company ' $\mathrm{C}$ ' is presently doing the business of, "an importing whole selling and distributing Pharmaceutical items. Currently, the company was holding a partnership with the international partners for main therapeutic areas, that company covers Dermatology, Mineralogy or Neurology, Oncology, and antibiotics etc." The company ' $C$ ' established an ERP system "from 01st of September 2016." Previously they used "a system call profit which covers most of the financial report and transactions, it had managed inventory control and invoicing process." After the fully acquired by other company, they use their system AS400 for the native system of the company ' $C$ '. The participant 
who was an Executive of the company ' $C$ ' said that, "we changed the system to AS400 which was the ERP of the acquired company at that moment AS400 was also more than enough for the company because we were able to integrate sales and distribution system with AS400." After implementing this system suddenly, they have to change to the new ERP system with a more integrated version of the SAP. This sudden system was to change by the acquired company on company $\mathrm{C}$, he said that, “... I think according to the acquired company concerned, we were forced to the system change, so I didn't have expert knowledge about the legacy system to explain the reason influenced for the changing from the legacy system. However, according to my knowledge, I think most probably acquired company faced problems like lack of storing capacity integration problems, vulnerability and lack of knowledge and understanding."

According to his knowledge the change of the ERP system to the SAP caused "... I think the acquired company has selected the SAP was the future of ERP. SAP follows best practices to a standardized business processes SAP allows customize the software to specific needs of the company has been integrated the SFA system with SAP system to get the systemize purchase orders and update the dispatches in the distribution. In addition to that at that time, SAP is user-friendly familiar looking which has a great graphical user interface mostly SAP improve the efficiency, effectiveness of the employees."

The consultancy services were provided by the foreign company to the implementation of the SAP to the company, which he said that "Our group had selected V-centric as consultants an implementation of the newer ERP. V-centric had implemented SAP as an ERP system for top companies in India, but this was, I think the first time that they engaged in the implementation of an ERP in Sri Lanka. Therefore, they didn't have much experience and knowledge about Sri Lanka economy and business matter so earlier we had complications with them and it was very difficult for us to explain and make them understand the current operation of our organization. So, ultimately we were able to put them on the track at the middle of the implementation."

To fulfil the requirements, considering above factors the company ' $\mathrm{C}$ ' decided to base on the acquired company affectation for use integrated ERP system, which was SAP for improve their performance of the sales and distribution system efficiently and effectively in the organization. The company ' $C$ ' was at the stage of post-implementation, because they have implemented ERP system only less than one-year period earlier.

Company D

Company ' $\mathrm{D}$ ' is a market leader among medicated candies in Sri Lanka. This product was very popular for its cooling menthol taste and it could be enjoyed as a "mouth freshener" or to offer temporary relief for throat irritation or cough. Initially it was imported from the United Kingdom from 1965, now its manufactured in Sri Lanka, as a franchiser.

Company ' $D$ ' can be categorized as an FMCG organization which was engaged in selling and distributing of food items. The ERP implementation started on " 3 rd
March 2016 but, it went on live on until $1^{\text {st }}$ of August 2016," as stated by the Senior Manager- Finance. This company was established more than fifty years of period, but they have not used a proper ERP system. According to the opinion of the participant, the reason for the change to the new ERP system was, "it was actually what happened for us to go for SAP we were in AS400 earlier was AS400 and at the time capacity utilization was around $95 \%$ to $96 \%$. So there was a threat that we might lose the existing software system or existing package we had and that's the main reason why we wanted to shift to ERP. Where the existing at that time AS400 work as an ERP solution only with the purchased finance module under the guidance of our IT manager's authority."

The company ' $\mathrm{D}$ ' also uses the SAP for their workaround solution as an ERP system. The reason for selecting a SAP for their ERP system was, "we are a subsidiary of main cluster congregate of Colombo Fort Land where the part of our subsidiaries already have gone to ERP. The mission was basically accepted that the associate inter people should go for SAP as ERP. Though, already one subsidiary had gone for SAP as ERP. Therefore, we were compelled to go for SAP as ERP solution, even we looked at other options like Oracle, IFS but the group mission was to go for SAP." The company ' $D$ ' also used foreign party as their implementation partner of an ERP system, and revealed the reason for that "... we had local parties, two local parties and one foreign party. But during the evaluation process we understood that most of the local parties also hiring foreign partners, foreign employees for the implementation of ERP. Further we were talking about ERP S/4 HANA, which was a very newer version that was 2015 November version that we were trying to implement. So as far as local experience concerned we didn't see anybody was having S/4 HANA implementation. So only the party which was found by our evaluation panel was foreign Indian party, who had plenty of experience on S/4 HANA implementation. And further SAP, as the main provider has recommended this foreign party for the implementation of S/4 HANA."

To fulfil the requirements, considering above factors the company ' $D$ ' decided to base on the acquired company affectation for use integrated ERP system, which was SAP for improve their performance of the sales and distribution system efficiently and effectively in the organization. The company ' $D$ ' was already at the stage of post-implementation, because they have implemented ERP system less than one-year period earlier.

\section{ANALYSIS OF FINDINGS}

The findings of the research study based on four cases described above.

\section{A. Objective 01: Present Situation of ERP Implementation}

According to the findings of the study, the all four cases are at the stage of ERP post-implementation. The review of those cases are using the SAP software as for their 
ERP system to integrate all the functionality in an organization. In the present situation of the ERP implementation all the four cases are slightly different in some factors. Most of the cases establishment of the ERP are under less than one-year period in the organization. Therefore, the users of the new ERP system were suffering from the lack of the knowledge and need more support from the consultations to doing the day-to-day operations in an organization.

All the cases, have used expertise knowledge for implementation ERP system from foreign parties. Therefore, they have to depend on third party consultation and support for day-to-day operations. That was a burden to users and if there is a problem they have to get support from the foreign party which was time consuming and loss of the operations at the immediate stages.

Another point is the delaying of the system implementation in an organization. Because of the ERP concept was established in early 1990s, but in Sri Lankan FMCG industry is new to ERP. According to the above four cases they are already using an ERP system, but it is not integrated to fulfil all the requirements of an organization.

Business process reengineering caused to change the culture of an organization as for the world acceptable culture. Cultural change more affected the employees in a bad way and that aroused resistant from the employees. A participant of the research says, “... certain user's legacy system report looks at it vast different therefore feel getting difficult to look at the information...", this was caused to increase resistant from the employees as well as management, because users' expectancy was higher than the system provided.

Objective 02 \& 03: Successful Factors and Difficulties of an ERP System Implementation

According to the above findings of the four cases, there are some successful factors and difficulties faced on the process of an ERP system implementation of an FMCG industry in Sri Lanka. Therefore, the study was limited to analysis the factors affecting to the ERP implementation of an FMCG industry, which includes home care, personal care, pharmaceutical and foods products categories.

\section{Success Factors of an ERP System Implementation}

The following findings could be reached through the analysis of the data regarding the above four cases, which are successfully affecting to the ERP system in an FMCG industry in Sri Lanka.

\section{Technology Complexity}

According to the above four cases mostly aware about the technological knowhow is more important in the implementation of an ERP system. Therefore, the super user concept could be introduced for obtaining the knowledge of expertise as an important strategy at the implementation process within the organizations. This concept is more prominent of an organization to finding the faults of an ERP system and to fulfil the knowledge gap of the technology knowhow.

\section{Information Dissemination}

Information's are more needful to an organization, because the top management are taking their decisions through an information flow of a system. The users of the ERP system are able to obtain standard reports; however, the top management have the advance control of the system. Likewise release strategy, authorization level of a system gives more accurate and reliable information to the users.

\section{Business Size}

The business sizes could be categorized as small, medium and large scale of business. According to the findings, a medium size of business organizations is more suitable in the implementation of an ERP system, because their processes are not complicated as in large scale businesses. Then they can easily be adopted to the new ERP system environment without any harmful effect to their existing processes.

\section{Business Process Re-Engineering Experience}

Business process re-engineering experience is not more essential part of an ERP system implementation of an organization, because of that an ERP system already have required details as an integrated way. The organization need to do only transferring the master data to the new ERP system from their legacy system. The master data are consisting of vendor master, customer master and material master. Therefore, there is one code to recognize the details of master, for an example the one vendor code is for only identification number of the supplier of an organization.

\section{Manufacturing Strengths}

The ERP system was more effective to a manufacturing processes because the ERP system built on the concept called Material Requirement Planning (MRP). Therefore, at the time of the implementation, it is difficult to adopt to the best practices in the ERP system, but after that manufacturing processes could be run smoothly and effectively in the post-implementation period.

\section{Government Regulations}

There is no any government regulation to implementation of an ERP system in an organization. But in post-implementation stage there have some requirements from the government institutions need to be fulfil by the organization. For an example detail required from Inland Revenue Department of Sri Lanka need to be collect information by the companies from their system, then organization need to submit their information through the ERP system. It is easy to the organization to fulfil the requirements of the government and government institutions.

\section{Management Commitment}

The sponsorship of the management is played more vital role in the ERP system implementation in an organization. At the time of the pre-implementation stage management need to decide the duration of the implementation of the ERP system and which ERP software is suit to the requirements of an organization. Therefore, the management need to look after the all the processes of an organization at the time of ERP system implementation as well as the post-implementation. The management need to review day-to-day operations through the ERP system and any 
deviations need to be take corrective action in the system. Regional Environment

The stakeholders of an organization are more important to the implementation of an ERP system in an organization. These stakeholders are mainly affecting to the decision making processes of an organization because of that these stakeholders are having separate requirements from the organization. For an example, vendors need to know liquidity of an organization and the security of their borrowings from the organization.

Difficulties of an ERP System Implementation

\section{Technology Complexity}

Technology knowledge is more important factor of an implementation of an ERP system. Therefore, it is essential that the knowledge in IT and also the technological knowledge about hardware and software. According to the findings of the study, it is essential that the use of more complex technology for the implementation of an ERP system. Then the companies are needed to spend more cost to fulfil the technological gap of their users. Not only that but also these companies have implemented new version of an ERP system for Sri Lankan context, then the organizations are needed to get foreign support during the pre-implementation, implementation and also the post-implementation process.

\section{Resource Utilization}

According to the findings of the study are denoted that all the organizations have to buy separate new hardware and software. The organizations have spent more money to the implementation of new hardware and also the utility software. Another point of that, the users of an organization need to have training for the usage of new hardware and software. That is more time consuming of an organization and it cause to block the day-to-day operations of an organization.

\section{Information Dissemination}

The ERP system providing more of the standardize reports to the users, but the users are more aware of their legacy system. Then they are more resists to the new system and they are obtaining information from the legacy system. If they want to get information from the new ERP system need to be customize of the report from generating of the ERP system, and it takes time after an implementation of the new ERP system.

\section{Business Logic Implementation}

The business culture is a wider role in an organization because it has created connectivity of employees and the managers of an organization. But after the implementation of an ERP system the organization need to follow the best practices which uniformity with world practices. These best practices are caused to change the culture of an organization to adopt to the world practices. The cultural change of an organization is faced more resistant from the users of an ERP system as well as from the management of an organization. Another thing was the user training needed with the best practices in an ERP system, therefore the organization need to spent more money to train all the users of an ERP system. The user training is a must, because of users are more to resist to the new system in a pre-implementation, implementation and also the post-implementation. The main reason for the resistance which comes from the users is changing of the legacy system to new ERP system and adopting the organization for that environment.

\section{Economy and Economic Growth}

The Sri Lankan economy was not growing compared to the world economic growth. That is badly affected to the implementation of an ERP system of an organization because of that ERP systems are more expensive to the organizations. If there is not growing of the economy makes trouble to the organization for the ERP implementation because the investment is not worthy. Therefore, the companies are needed to invest in an ERP system at the stage of the growing economy in Sri Lanka. But after the implementation of an ERP system is not much more contribute to the economic growth at the time of just implementation of the ERP in Sri Lankan FMCG industry. Therefore, the organizations are within the learning curve period of the system best practices and they have to learn more about the best practices which is implemented by an ERP system.

\section{Business Size}

If the business size is in large scale, there have to use more complicated business processes to implement an ERP system. The large scale business processes are need to be comprised to equal to the best practices of an ERP system. Therefore, the large scale businesses may not be adopting to the new ERP system or resist to adopt to an ERP system.

\section{User Training}

The organization need to train users of an ERP system to gain a better understanding of an ERP system and to obtain the better output from the system. Therefore, during the limited time of period in the process of an implementation the ERP system, there were not enough time to make the way to a thorough training to the users. At the time of post-implementation users are undergoing training on the job and face more difficulties to do the job role efficiently. It is an additional cost to the organization.

\section{Employee Engagement and User Involvement}

Employees are one of the driving factor of an organization that is to be considered as the human capital which invests in an ERP system. Therefore, users need to be involved actively in the implementation in an ERP system in an organization. If there are no involvement of the users, the organization could not achieve their goals.

\section{Leadership}

Leadership is another important thing in an ERP system implementation of an organization. An ERP system implementation of an organization is a project, every project team have a leader to give the instructions and get the involvement from the users. If there is not a proper leadership all the project may be crashes and loss the investment of an organization. 


\section{Consultancy Service}

The consultants are more need to the ERP system implementation because of that they have more knowledge of the system as well as the best practices of the ERP system. Therefore, the consultant need to know more about the system as well as the existing situation of the organization. But all four cases are used foreign party as for an ERP system implementation partner that because more burden to the organization to train them about the existing business culture of an organization.

Objective 04: Performance Measurement of an ERP System Implementation

The final objective of an ERP system implementation of an organization is an achieving the goals. The organization need to introduce a tool for measuring their performance through the new ERP system and make the way to obtain better decisions for overall organization. Therefore, they need to use Key Performance Indicator (KPIs) to measure their performance through an ERP system.

All the four cases studied need to make arrangements to measure the performance of the organization. However, the case studied under company ' $A$ ', they have done just the implementation of an ERP system and they are not in a position of obtaining reports from the system itself. The company ' $A$ ' suggested a new tool called Business Intelligence (BI) and it is used for generating the report from the ERP system and the management can observe the organizational performance.

Already the company ' $\mathrm{B}$ ' is doing the performance measurement only through the employee engagement of the new ERP system. Apart from that, currently there is not any accurate performance measurement system functioning in their ERP system within the organization. The company ' $C$ ' is using system reports like sales reports, inventory reports, and financial reports etc. as indicators to measure the performance of the organization. As the KPIs they use some characters like supply chain performance, inventory management, accounting procedures and debtor collection period of the organization.

The company ' $\mathrm{D}$ ' had implemented their ERP system within a shorter period and made arrangements to measure performance at the stage of the pre-implementation. At the stage of the pre-implementation they have used the KPI as cost management of the project. Other than that, after the implementation of an ERP system they used “... some KPI of information how faster your information is for an example we are a production company how faster we can get review of the production wastage, information utilization of the production wastage..."

\section{CONCLUSION}

According to the findings of the study the ERP system implementation is more difficult task to the organization. Most of the organizations wanted to change their legacy system to the new ERP system platform but some legacy system information is not available as same as in the new ERP system. Therefore, the organization need to change their legacy system to suit to the new ERP system platform because some legacy information will not compatible to the new ERP system. To overcome that problem the organization should make necessary arrangements to convert legacy information to the best practices of the new ERP system.

Another finding of the research study, users training is more useful to a successful continuous process of the ERP system in an organization. If users are not aware about the new system, the users will resist to the system and the organizational achievements will be delayed.

The findings regarding the management commitment and the leadership are more important in the pre-implementation and also in the post-implementation in an ERP system implementation. Therefore, the top management and the mangers need to check the performance of the ERP system and take corrective actions against any deviation from the best practices in an organization.

\section{REFERENCES AND NOTES}

[1] Abosede, J. (2016). Research Design: A Review of Features and Emerging Developments. European Journal of Business and Management, 8(11), 113-118.

[2] Adebanjo, D., \& Mann, R. (2000). Identifying Problems in Forecasting Consumer Demand in the Fast Moving Consumer Goods Sector. Benchmarking: An International Journal, 7(3), 223-230.

[3] Agarwal, P. G. D. (2014). Critical success factors for ERP implementation in a Fortis hospital: an empirical investigation. Journal of Enterprise Information Management, Vol. 27(Iss 4), 424-448.

[4] Almgren, K., \& Bach, C. (2014). ERP Systems and their Effects on Organizations : A Proposed Scheme for ERP Success. ASEE 2014 Zone I Conference, $1-5$.

[5] Bourgeois, D. T. (2014). Information Systems for Business and Beyond.

[6] Braun, V. \& Clarke, V. (2006). Using Thematic Analysis in Psychology, 3, 77-101. https://doi.org/10.1191/1478088706qp063oa

[7] Burns, N. \& Grove, S. K. (2003). Understanding Nursing Research. 3rd ed. Philadelphia: Saunders Company.

[8] Carolina, N. (1992). ERP implementation issues in advanced and developing countries, 7(3), 276-284.

[9] Diehl, D., \& Spinler, S. (2013). Defining a common ground for supply chain risk management - a case study in the fast-moving consumer goods industry. International Journal of Logistics Research and Applications, 16(4), 311-327.

[10] Dunaway, M. M. (2015). Chapter 4: ERP Implementation Methodologies and Strategies.

[11] Dupre, K., \& Gruen, T. W. (2004). The Use of Category Management Practices to Obtain A Sustainable Competitive Advantage In The Fast-Moving-Consumer-Goods Industry. Journal of Business \& Industrial Marketing, 19(7), 444-459.

[12] Fereday, J., \& Muir-Cochrane, E. (2006). Demonstrating Rigor Using Thematic Analysis: A Hybrid Approach of Inductive and Deductive Coding and Theme Development. International Journal of Qualitative Methods, 5(1), 80-92.

[13] Fosser, E., Leister, O. H., \& Moe, C. E. (2008). ERP SYSTEMS AND COMPETITIVE ADVANTAGE : SOME INITIAL RESULTS 1.

[14] Gayan, R. B. A., Rameshkanna, Y., Ratheesan, R., Senevirathne, S. W. M. A. I., Mangala, K. H. J., Bandara, D. S. V., ... Bandara, D. S. V. (2015). Process Optimization of Sri Lankan Saucepan Manufacturing Industry by Time Study Analysis. Annual Technical Conference 2015 of IET-YP Sri Lanka, Accepted(July), 5-10.

[15] Jaiswal, M. P., \& Kaushik, A. (2005). Realising enhanced value due to business network redesign through extended ERP systems: Case study of HLLNet. Business Process Management Journal, 11(2), 171-184.

[16] Kunc, M. H. (2005). Illustrating the Competitive Dynamics of an Industry: The Fast-Moving Consumer Goods Industry Case Study. Proceedings of the 23rd International Conference of the System Dynamics Society, 96. 
[17] Lõun, K., Riives, J., \& Otto, T. (2011). Evaluation of the operation expedience of technological resources in a manufacturing network. Tehnoloogiliste Ressursside Kasutamise Otstarbekuse Hindamine Tootmisvõrgustikus, 17(1), 51-65.

[18] Madurapperuma, T. S., Thelijjagoda, S., Ramanayaka, R. A. D. K. M., Walpola, D. R. H., \& Thelijjagoda, S. (2009). ERP Deployment in Manufacturing Industry in Sri Lankan Context. Psrs, 3, 49-53.

[19] Marshall, M. N. (1996). Sampling for qualitative research. Family Practice, 13(6), 522-525.

[20] Mishra, A., \& Mishra, D. (2010). ERP SYSTEM IMPLEMENTATION IN FMCG SECTOR.

[21] Motwani, J., Subramanian, R., \& Gopalakrishna, P. (2005). Critical factors for successful ERP implementation: Exploratory findings from four case studies, 56, 529-544.

[22] Myers, M. D. (1997). Qualitative Research in Information Systems, (June).

[23] Nanayakkara, K. S., Perera, P., \& Perera, A. (2015). Factors Incompatibility of Selection and Implementation of ERP Systems for Construction Organizations - Lessons from Sri Lanka. International Journal of Computer Science and Technology, 6(3), 9-15.

[24] Nemati, S. A., \& Mangaladural, D. (2014). Impact of Enterperise Resource Planning in Supply Chain Management, 1-5.

[25] Noor, K. B. M. (2014). Case Study: A Strategic Research Methodology, 5 (11), 1602-1604.

[26] Palawatta, I. T., \& Perrera, H. S. C. (2016). Inventory Optimization Using ERP to Reduce Final Product Lead Time, Inventory Value and Inbound Logistics Costs for MTO, FMCG Company. International Journal of Multidiscipliary Studies (IJMS), 3(2), 53-60.

[27] Parahoo, K. (1997). Nursing Research: Principles, Process, and Issues, 403.

[28] Rajapakse, J., \& Seddon, P. B. (2005). Why ERP may not be Suitable for Organisations in Developing Countries in Asia, 1382-1388.

[29] Shatat, A. S., \& Mohamed Udin, Z. (2012). The relationship between ERP system and supply chain management performance in Malaysian manufacturing companies. Journal of Enterprise Information Management, 25(6), 576-604.

[30] Singh, J. (2014). FMCG ( Fast Moving Consumer Goods ) An Overview. International Journal of Enhanced Research in Management \& Computer Application, 3(6), 14-16.

[31] Thoren (2000). Data Analysis in Qualitative Research, 68-70.

[32] Umble, E. J., Haft, R. R., \& Umble, M. M. (2003). Enterprise resource planning: Implementation procedures and critical success factors, 146, 241-257.

\section{AUTHOR PROFILE}

\section{H M R P Herath}

Currently I am affiliated with Department of Marketing Management, University of Kelaniya, Sri Lanka and my area of research is Enterprise Resource Planning (ERP) System.

S I Wijenayake

I am S I Wijenayake from Department of Marketing Management, University of Kelaniya, Sri Lanka, and my area of research is Enterprise Resource Planning (ERP) System. 